\title{
EDUCAÇÃO E DESENVOLVIMENTO DO PSIQUISMO: UMA ANÁLISE HISTORICO-CULTURAL ACERCA DESSA CORRELAÇÃO
}

${ }^{1}$ Vinicius dos Santos Oliveira, ${ }^{1}$ Evelyn de Paula Souza, ${ }^{2}$ Irineu Aliprando Tuim Viotto Filho, ${ }^{2}$ Rosiane de Fatima Ponce.

${ }^{1}$ Universidade do Oeste Paulista - UNOESTE, Presidente Prudente, SP. ${ }^{2}$ Universidade Estadual Paulista - UNESP. Email: violiveirapp@hotmail.com; eve.paula@hotmail.com.br; tuimviotto@gmail.com; rosianeponce@uol.com.

\section{RESUMO}

O presente ensaio teórico visa realizar uma discussão sobre o processo de desenvolvimento do psiquismo e as contribuições da educação escolar com base na teoria histórico-cultural e na pedagogia histórico-critica, teorias que compreendem o ser humano como um sujeito dialético que se desenvolve à medida que tem contato com a cultura, história e coletividade humana. Por meio da educação escolar é possível desenvolver o psiquismo em suas máximas possibilidades, por meio do trabalho educativo do professor e da transmissão de conhecimento humano-genérico na escola.

Palavras-Chave: Educação; teoria histórico-cultural; desenvolvimento do psiquismo.

\section{EDUCATION AND PSYCHISM DEVELOPMENT: A HISTORICAL-CULTURAL ANALYSIS ABOUT THIS CORRELATION}

\begin{abstract}
This theoretical essay aims to make a discussion about the development process of the psyche and the contributions of education, based on the cultural-historical theory and historical-critical pedagogy, theoretical approaches which understand the human being as a dialectical being that build its development in the contact with the culture, history and human collectivity. Through schoolar education it is possible to develop the psyche in its maximum possibilities, through the teacher educational work which will emphasize the transmission of the human-generic knowledge inside the school.
\end{abstract}

Key Words: Education; historical- cultural theory ; development of the psyche

\section{INTRODUÇÃO}

Este ensaio teórico tem o objetivo de realizar uma discussão acerca do desenvolvimento do psiquismo e as contribuições da educação escolar neste processo pois, o ser humano nasce como representante da espécie homo sapiens, no entanto, para pertencer ao gênero humano precisa passar por um processo educativo e, neste sentido, além da família, a educação escolar assume importância fundamental nesse processo se humanização, ou seja, na transformação do ser homo, representante da espécie, em ser humano humanizado.

É por meio da apropriação dos signos culturais, da convivência em sociedade e do trabalho educativo que há a possibilidade de humanização dos seres humanos, bem como, quanto mais apropriações o individuo tiver dos bens materiais e simbólicos, dentre eles os conhecimentos produzidos pela humanidade, mais humanizado ele será. A partir disso, defenderemos que a transmissão dos conhecimentos historicamente produzidos e sistematizados pela humanidade deve ser realizada pela escola, por meio da atividade educativa do professor.

Esta é uma produção de cunho teórico com base em pesquisa aos textos clássicos e contemporâneos da teoria histórico-cultural e da pedagogia histórico-crítica.

\section{FUNDAMENTAÇÃO TEÓRICA}

Compreendemos o ser humano como ser social, produto de suas apropriações, ou seja, síntese do apoderamento de conhecimentos e da 
cultura produzida pelas gerações precedentes. Cada ser humano nesse processo de apropriação, portanto, aprende a ser humano, sendo que a principal característica da apropriação da cultura é que, por meio dela, são desenvolvidos no ser humano novos órgãos funcionais (LEONTIEV, 1978), ou na expressão de Vigotski, Funções Psicológicas Superiores, capacidades especificamente humanas. (DUARTE, 1993; LEONTIEV, 1978; VIOTTO FILHO, 2012).

Ao falar da natureza social do psiquismo, não há que contestar que o que dá sustentação para o desenvolvimento do psiquismo é a materialidade orgânica dele, obviamente, pois, por meio das respostas orgânicas ao meio, reações inatas e reflexos presentes nos animais, inclusive no animal representante da espécie homo, é que foi possível a garantia da vida e da existência no mundo, no entanto, como as pesquisas em psicologia do desenvolvimento tem comprovado, os seres humanos avançaram na sua constituição física (hominização) e psíquica (humanização) e constituíram-se seres humanos dotados de um cérebro altamente desenvolvido, capaz de desenvolver neoformações essenciais para 0 desenvolvimento do pensamento, da linguagem, dos sentimentos e da consciência, diferenciandose das outras espécies animais.

Podemos afirmar que em decorrência da evolução biológica do cérebro é que aconteceu a grande diferenciação dos homens para os animais, enfatizando que esse processo de evolução não se deu natural e espontaneamente, mas decorrente do trabalho que os representantes da espécie humana realizaram na sua relação com a natureza, desde os primórdios da história humana na terra.

Para Luria (1989, p.194) "os processos psicológicos surgem não no interior da célula viva, mas em suas relações com o meio circundante, na fronteira entre o organismo e o mundo exterior". Para o autor, a consciência, nesse processo de desenvolvimento, "assume as formas de um reflexo ativo do mundo exterior que caracteriza toda atividade vital do organismo", ou seja, é na atividade do meio circundante que concretiza-se o desenvolvimento do psiquismo humano, fenômeno que, espontaneamente, seria impossível (ANJOS, 2013; MARTINS, 2011; VIOTTO FILHO, 2007 e 2012).

Viotto Filho (2007) a partir dos estudos de Leontiev (1978), afirma que entender a categoria atividade é fundamental para a compreensão humana na perspectiva da Psicologia Histórico-Cultural. O autor define que é por meio dessa compreensão da atividade que se chega ao entendimento da essência genérica do homem, aquela construída social e historicamente. Esta deve ser vista como um sistema estruturado e em desenvolvimento e transformação contínuos, tendo por finalidade a orientação do individuo em meio ao mundo objetivo, concreto, possibilitando ao homem processos de transformação e mudanças internas.

É importante esclarecer que embora internas, tais mudanças no ser humano, não podem ser vistas como naturais, desconsiderando-se que a atividade humana tem sua origem nas relações externas, sociais, assim como os motivos e necessidades da atividade consciente humana tem sua gênese nas relações sociais. Portanto o lugar que o sujeito ocupa socialmente em relação à sua classe, condições objetivas de vida e mediações constituintes de sua individualidade, altera e influencia a maneira que essa atividade se concretiza (VIOTTO FILHO, 2007).

Se o ser humano se desenvolve fundamentalmente por meio da atividade de trabalho, é nessa atividade que se desenvolvem suas funções psíquicas superiores. Sendo assim, podemos afirmar que a atividade faz com que as funções elementares do psiquismo humano tornem-se complexas, sendo elas, capazes de regular não somente as capacidades cognitivas do homem, como também seus sentimentos, comportamentos, consciência e personalidade.

O trabalho é compreendido como uma relação dialética do homem com a natureza, como apregoou Marx, em que, nesse processo de relação com a natureza e com outros seres humanos, ao mesmo tempo que o indivíduo se humaniza, ele também humaniza o outro, os outros e esse fenômeno social de desenvolvimento se dá por meio da realização coletiva do trabalho material e não material (ANJOS, 2013; DUARTE, 1993; LEONTIEV, 1978; MARTINS, 2011; SAVIANI, 2003; VIOTTO FILHO, 2007).

O trabalho material se traduz por aquele tipo em que o homem produz sua existência modificando a natureza em busca de satisfazer suas necessidades. Neste modelo, ele produz bens materiais, instrumentos objetivos de trabalho. Já o trabalho não material, refere-se à 
atividade intelectual, que produz conhecimentos os quais, pela via da linguagem de significados, são transmitidos às gerações mais jovens. Nesta segunda forma de trabalho encontra-se a educação, em que há a transmissão dos conhecimentos e da cultura aos mais novos (SAVIANI, 2011).

Reiterando o que afirmamos acima resgatamos a afirmação do autor:

O processo de produção da existência humana implica, primeiramente, a garantia da sua subsistência material com a consequente produção de bens materiais e esse processo é denominado de trabalho material (...) Para produzir materialmente, o homem necessita antecipar em ideias os objetivos da ação (...) o homem representa mentalmente os objetivos reais que deseja atingir e abre a possibilidade de uma outra categoria de produção, a do trabalho não-material (SAVIANI, 2011).

Para o autor, o trabalho não material trata da produção de ideias, conceitos, valores, símbolos, hábitos, atitudes, ou seja, trata-se da produção do saber e, nesse sentido, a construção do conhecimento passa pela apropriação de outros conhecimentos pensados e sistematizados pela humanidade, acumulando, portanto, bens não materiais humano-genéricos, porque essenciais à construção da humanidade, do gênero humano.

Quanto às funções psíquicas, também decorrentes do processo de apropriação da linguagem e dos conhecimentos construídos historicamente, as mesmas se constituem como parte integrante do psiquismo humano, o qual se manifesta como uma "imagem subjetiva do mundo objetivo", como afirma Martins (2011). É a representação psíquica da realidade objetiva e, nester caso, a imagem psíquica desenvolve-se por meio da complexificação da estrutura orgânica e através da atividade social. Aqui se encontra a materialidade da própria consciência, pois os fenômenos objetivos, as objetivações humanas já existem no mundo antes do sujeito que se apropria delas para, desta feita, incorporá-las subjetivamente e impregná-las na sua maneira de ser e existir na sociedade, ou seja, nos seus pensamentos, sentimentos, consciência e na sua personalidade (MARTINS, 2011; LEONTIEV, 1978).

Tal imagem subjetiva, conforme aponta Martins (2011), não é uma cópia fiel e mecânica da realidade. A atividade humana se manifesta por meio de atos, os quais fazem o homem se firmar na realidade objetiva, ao passo que transforma esta objetividade em subjetividade. A vivência psíquica de cada ser humano, portanto, é produzida através relação de cada sujeito com o mundo externo e somente se institui com base nessa relação. Para ilustrar ainda mais essa afirmação, lembramos Leontiev (1978, p.266) quando reitera que "se as crianças se desenvolverem fora da sociedade e dos fenômenos por ela criados, o seu nível é o dos animais. Não possuem nem linguagem nem pensamento".

A atividade humana é em principio uma atividade prática, externa, a qual é parte de um processo dialético onde o ser humano já contém, desde o principio, componentes psíquicos subjetivos. "Isso significa que é ao longo do desenvolvimento que a atividade mental se desprende da atividade objetiva externa, o que ocorre como resultado de sua interiorização" (MARTINS, 2011, p. 29).

Não é possível separar a atividade individual (externa e interna) da atividade social, coletiva e cultural porque a dinâmica de internalização humana é um processo de transição de processos interpsíquicos para processos intrapsíquicos. Tal internalização acontece através da apropriação dos signos que se constituem mediadores das relações humanas com a cultura produzida, sendo assim, ela, a apropriação dos signos, é central no desenvolvimento do psiquismo (MARTINS, 2011).

Inferimos que a cultura, seja do senso comum ou do conhecimento científico, promove o desenvolvimento psíquico, e desta forma, humaniza os seres humanos. No entanto, não da mesma forma e com a mesma qualidade. O conhecimento mais elaborado, o saber sistematizado e científico desenvolve as funções psíquicas em suas máximas possibilidades e engendra o pensamento crítico e conceitual. Por isso, defendemos, então, a necessidade da instituição escolar transmitir o saber sistematizado e não cotidiano, conforme apontado por autores da Pedagogia HistóricoCritica e da Psicóloga Histórico-Cultural (DUARTE, 
1993; LÍGIA, 2012; SAVIANI, 2011; MALANCHEN; ANJOS, 2013).

A escola passa a ter importância fulcral no tocante à proporcionar para a criança a apropriação da cultura produzida historicamente pela humanidade, instrumentos fundamentais para a comunicação e relação do aluno com o meio social. Também a assimilação de novos conhecimentos constitui-se fundamental para o ensino e para o desenvolvimento complexo do psiquismo. Neste rumo Facci (2004) aponta ser importante o ensino escolar por possibilitar a aquisição de conhecimentos específicos, sobretudo os científicos, que produzem condições diferenciadas para a construção e desenvolvimento das funções psicológicas superiores humanas.

Martins (2011) aponta que a transmissão do conhecimento sistematizado é condição indispensável para o desenvolvimento humano. Referenciando-se em Vigotski, afirma que as funções complexas da mente são desenvolvidas por meio da apropriação deste conhecimento que é transmitido pelo professor na escola, uma vez que "o trabalho educativo é o ato de produzir, direta e intencionalmente, em cada sujeito singular, a humanidade produzida histórica e coletivamente, pelo conjunto dos homens" (SAVIANI, 2011, p. 13)

No tocante à educação escolar, Martins (2011) pontua, ainda, que cabe a ela, confirmar e legitimar o desenvolvimento do pensamento científico, pois pensar por conceitos permite 0 avanço da experiência para as ações intencionais, permite ao individuo ir além da espontaneidade proporcionada pelas funções psíquicas elementares por meio da aquisição e ampliação dos signos culturais. É cargo da educação sistematizada da escola proporcionar ao estudante estes novos conceitos que devem superar ideias adquiridas cotidianamente e possibilitar sistematização do conhecimento.

Nesse caminho, Vigotski escreve sobre o desenvolvimento dos conceitos científicos e a necessidade do processo educacional:

O curso do desenvolvimento do conceito científico nas ciências sociais transcorre sob as condições do processo educacional, que constitui uma forma original de colaboração sistemática entre $o$ pedagogo $e$ a criança, colaboração essa em cujo processo ocorre o

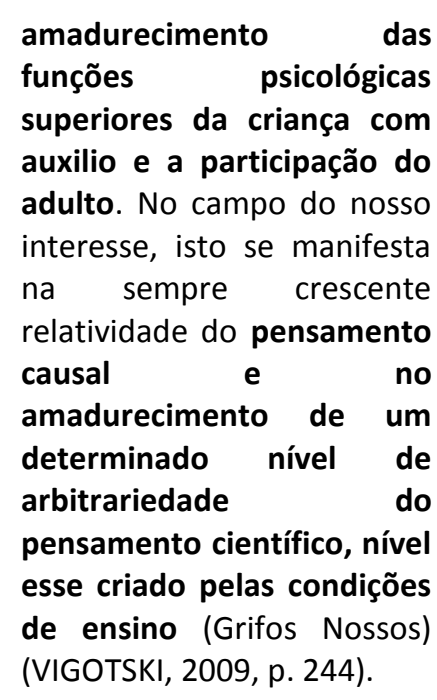

No fragmento supracitado Vigotski afirma que na escola deve haver uma relação de cooperação do professor com o aluno para a introdução da forma de pensamento por conceitos científicos, o que deve ocorrer de forma sistematizada, pois assim, ele potencializará na criança o desenvolvimento das funções superioras ao passo que possibilitar o aprendizado do conhecimento cientifico e sistematizado, mais elaborado já produzido.

Vigotski (2012) afirma que a função reitora, principal para todo o desenvolvimento do pensamento é a formação dos conceitos. Afirma que todas as outras funções se unem a ela. $O$ pensamento conceitual intelectualiza e reorganiza o pensamento. $O$ autor utiliza a função da percepção para exemplificar tal fato dizendo que é graças ao pensamento que os objetos isolados da percepção conseguem se relacionarem entre si. Pelo pensamento há a aquisição de sentido para aqueles objetos. E a linguagem faz a função elementar se tornar superior, pois ela permite realizar uma análise da realidade.

Neste caso a colaboração do adulto ou professor para com a criança é central no processo educativo, pois nesse mesmo momento pode acontecer o desenvolvimento de conceitos que estão na "zona das possibilidades imediatas em relação aos conceitos espontâneos" (VIGOTSKI, 2009, p. 244). Para o autor mesmo a criança desenvolvendo novos conceitos científicos, os adquiridos cotidianamente continuam existindo. Ou seja, o educador que reproduzir o bom ensino estará adiantando o ensino em relação ao desenvolvimento, sempre havendo uma relação dialética entre ensino e desenvolvimento. 
Vigotski (2014) discorre sobre a importância de estudar o desenvolvimento dos conceitos científicos na criança em idade escolar. Ele afirma que com o desenvolvimento dos conceitos científicos segue um caminho particular, diferente do desenvolvimento dos conceitos cotidianos. Por isso há a necessidade da cooperação de forma especial do pedagogo com a criança.

Vigotski (2009) define que conceito é uma atitude complexa do pensamento e não está apenas ligado à memória. Para que a criança adquira um conceito precisa estar potencialmente preparada (Zona das Possibilidades Imediatas). Afirma ainda que conceito é o ato de generalizar e expressar a generalização por meio da palavra. Ao mesmo tempo, vai-se gerando significados mais complexos para cada conceito.

Por meio dos signos "[...] o psiquismo humano adquire um funcionamento qualitativamente superior e liberto tanto dos determinismos biológicos quanto do contexto imediato de ação" (p. 133). Os signos ajudam na solução de problemas da mesma forma que um instrumento de trabalho, que o trabalhador precisa adaptar-se a ele. Por conseguinte, o signo tem semelhanças a um instrumento (MARTINS, 2011). É por meio deles, por exemplo, que não precisamos amarrar um laço no dedo a cada tarefa a ser lembrada em nosso cotidiano. Ou seja, assim como os instrumentos auxiliam e mediam a atividade externa do homem, o mesmo ocorre com os signos em frente às atividades internas, psíquicas do individuo.

Portanto, o desenvolvimento das atividades mais complexas somente acontece quando mediadas e apresentadas de forma a exigir um pensamento superior do aprendiz. Em relação a isto Martins (2011, p. 135) afirma que:

[...] do ponto de vista psicológico, a construção do conhecimento objetivo carrega consigo outras exigências, dentre as quais se destaca o próprio desenvolvimento do pensamento. $\mathrm{Na}$ qualidade de função psíquica superior, o desenvolvimento do pensamento é uma conquista advinda de condições que o promovam e o requeiram
- e, como tal, depende em alto grau das dimensões qualitativas da formação escolar (Grifos Nossos).

A escola nesta fase do desenvolvimento precisa ser capaz de proporcionar ao aluno, formas sistematizadas de aquisição do conhecimento acumulado durante a história da humanidade. Seja qual for a disciplina, ela deve dar ao estudante possibilidade formação de novos conteúdos, de novos conceitos sistemáticos e complexos.

O professor necessita conhecer quais as atividades que guiam o desenvolvimento psíquico do estudante, em cada etapa do desenvolvimento humano para possibilitar a este aluno $o$ ensino que vem antes do desenvolvimento, ou seja, trabalhar na Zona de Desenvolvimento Próximo, como proposto por Vigotski e Elkonin. Malanchen e Anjos (2013, Apud Saviani, 2003) que definem que, identificar quais os conteúdos a serem transmitidos para os alunos é de fundamental importância para o desenvolvimento e evolução humana e também quais conteúdos produzidos historicamente devem ser escolhidos e incluídos no currículo escolar de forma a torná-lo realmente instrumentos para a liberdade e autonomia do ser humano.

Acreditamos que a reflexão sobre o desenvolvimento humano nos permita compreender de fato a importância do trabalho educativo do professor em frente à formação desses indivíduos enquanto homens. Assim como o papel fundamental da escola durante todo esse período e o quanto a educação se correlaciona nesse desenvolvimento de capacidades especificamente humanas.

\section{CONSIDERAÇÕES FINAIS}

Conforme Martins (2011) o conhecimento acumulado e sistematizado, condensados e organizados em conceitos devem ser ensinados e isto é uma atribuição da escola. Acrescenta, ainda, que Vigotski acredita que é o ensino que promove o desenvolvimento, onde somente pela transmissão do conhecimento e da cultura é possível humanizar uma pessoa. É o ato educativo que produz desenvolvimento de funções superiores - o caso desta pesquisa, o pensamento.

Sobre trabalho educativo - função do professor, Saviani (2003) afirma que ao produzir 
de forma direta e intencional no indivíduo a humanidade produzida historicamente pelos homens, compreendemos a função humanizadora da educação escolar que deve transmitir aos estudantes o conhecimento humano-genérico (mais desenvolvido) já construído pela humanidade.

Assim sendo, Saviani (2003) afirma que - objetivo da educação diz respeito à identificação dos elementos culturais que precisam ser assimilados pelos homens, fazendo com que eles se tornem humanos e por outro lado, cabe também descobrir e construir as melhores formas para atingir tal objetivo. Portanto, Malanchen e Anjos (2013), afirmam com base em Saviani, que a educação é uma atividade exclusivamente humana, ou seja, um processo de trabalho eminentemente humanizador.

Se educação é em si um processo de trabalho, logo, a natureza da educação é o próprio trabalho educativo humanizador que resume-se na transformação da primeira natureza, aquela natural e biológica, em segunda natureza, aquela construída social e historicamente na relação com os outros homens e na apropriação dos bens culturais. Portanto, a especificidade da educação é socializar o conhecimento, definindo os meios como serão socializados e apropriados pelos seres humanos na escola, ou seja, buscar formas eficazes e adequadas para tornar público à humanidade os conhecimentos construídos por ela mesma (SAVIANI, 2003).

Não compreendemos essa tarefa como uma simples atividade de transmissão, pois os alunos são ativos no processo de apropriação dos conhecimentos e não reconhecemos essa atividade como exclusiva do professor, pois na escola e na sociedade, todos estamos nos apropriando de conhecimentos, porém, na escola há que se garantir a transmissão daqueles conhecimento que não adquirimos no cotidiano, quais sejam, os conhecimentos construídos pela filosofia, pelas ciências, pelas artes, pela política, pela ética, dentre outros conhecimentos humano-genéricos.

O professor, bem como os demais educadores das crianças e jovens na escola necessitam oportunizar o desenvolvimento psíquico guiando a aprendizagem desses sujeitos por meio do ensino e da transmissão do conhecimento produzido e acumulado historicamente, como temos afirmado. Se na escola for possível que a criança aprenda os conteúdos clássicos e científicos, tanto mais ela poderá se desenvolver numa direção humanogenérica e avançar ao seu desenvolvimento cotidiano pois, como sabemos, de conhecimentos do senso comum a sociedade está repleta, no entanto, os conhecimentos humano-genéricos, somente na escola eles são encontrados.

\section{REFERÊNCIAS}

ANJOS, R. E. O Desenvolvimento Psíquico na Idade de Transição e a Formação da Individualidade Para-Si: Aportes Teóricos Para a Educação Escolar de Adolescentes. 2013, 167 f. Dissertação (Mestrado em Educação Escolar)Faculdade de Ciências e Letras, UNESP, Araraquara, 2013.

DUARTE, N. A individualidade para-si: contribuição a uma teoria histórico-social da formação do indivíduo. 1. ed. Campinas: Autores Associados, 1993.

FACCI, M. G. D. A periodização do desenvolvimento psicológico individual na perspectiva de Leontiev, Elkonin e Vigostski. Cadernos Cedes, Campinas, v. 24, n.

62 , p. 64-81, abr. 2004. Disponível em http://www.cedes.unicamp.br

LEONTIEV, A. N. O desenvolvimento do Psiquismo. 1 ed. São Paulo: Ed. Moraes, 1978.

LURIA, A. O cérebro e a atividade consciente. In: Vigotsky, L. S.; Leontiev, A. N.; Luria, A. Linguagem, desenvolvimento e aprendizagem. São Paulo: EDUSP, 1989.

MALANCHEN, J.; ANJOS, R. E. O papel do currículo escolar no desenvolvimento humano: contribuições da pedagogia histórico-crítica e da psicologia histórico-cultural. Germinal: Marxismo e Educação em Debate, Salvador, v. 5, n. 2, p. 118-129, dez. 2013.

MARTINS, L. M. O Desenvolvimento do Psiquismo e a Educação Escolar: contribuições à luz da psicologia histórico cultural e da pedagogia histórico-crítica. 2011, 250 f. Tese (LivreDocência) - Departamento de Psicologia, Faculdade de Ciências, UNESP, Bauru, 2011.

SAVIANI, D. Escola e democracia. 37. ed. Campinas: Autores Associados, 2003. 
SAVIANI, D. Pedagogia histórico crítica: primeiras aproximações. 11. ed. Campinas: Autores Associados, 2011.

VIGOTSKI, L. S. A construção do pensamento e da linguagem. 2. ed. São Paulo: WMF Martins Fontes, 2009.

VYGOTSKI, L. S. Obras escogidas. Madrid: Machado Grupo de Distribuición, 2014. t.2.

VYGOTSKI, L. S. Obras escogidas. Madrid: Machado Grupo de Distribuición, 2012. t.4.

VIOTTO FILHO, I. A. T. et. al. Psicologia e educação perspectivas criticas para a ação psicopedagógica. 1. ed. Birigui: Boreal, 2012
VIOTTO FILHO, I. A. T. Psicologia históricocultural: contribuições para a ação do educador numa escola em transformação. Revista de Educação Educare et Educare, v.2, n. 3, p. 49-68, jan./jun. 2007.

Recebido para publicação em: 26/04/2016 Revisado em: 29/04/2016

Aceito em: 02/05/2016 